This is an Accepted Manuscript of an article published by Taylor \& Francis in New Genetics \& Society on 09/05/2017. The article is available online here:

http://www.tandfonline.com/doi/full/10.1080/14636778.2017.1320943

To cite: Kragh-Furbo, Mette and Tutton, Richard. 2017. Spitting Images: Remaking Saliva as a Promissory Substance. New Genetics and Society.

http://dx.doi.org/10.1080/14636778.2017.1320943

\title{
Spitting Images: Remaking Saliva as a Promissory Substance
}

\begin{abstract}
Of the bodily substances in which STS scholars, anthropologists, sociologists, and medical historians have been interested, saliva has arguably been overlooked. Yet, in the past twenty years, saliva has become important to the development of consumer genetic tests. Historically, expectoration has been associated with the spread of disease and social indecency, but when the personal genomics company 23andMe began hosting spit parties in 2007, the act of spitting was transformed into an act of self-empowerment through which the individual gained new health information and saliva turned into a new biological source for measuring health and illness. Attending to saliva's social meanings over time, and by analysing 23 andMe "unboxing" YouTube videos, we argue that saliva has become a promissory substance whose place is no longer reserved only for the inner spaces of the body, but circulates outside the body, forming an important part of the contemporary bioeconomy.
\end{abstract}

Keywords: biocapital, biovalue, bodily commodification, personal genomics, saliva

\section{Introduction}

A substantial body of critical work has developed in the past decade about online consumer genetic testing, in particular the emergence in 2007 of "personal genomics" (Groves and Tutton 2013; Hogarth et al. 2008; McGowan et al. 2010; McGuire et al. 2009; Prainsack et al. 2008; Saukko et al. 2010). In drawing together practices of predictive genetic testing, the science of genetic association studies, and Web 2.0 techniques, personal genomics has been of immense interest to social scientists and bioethicists concerned with how services are marketed and regulated, the quality of information produced by companies, and how users interpret and act on this information. In all of the commentary and analysis that has been produced on personal genomics, relatively limited attention has been given to the significance of saliva to the commercialization of genetic testing as an online business.

The general lack of discussion about saliva and its place in personal genomics reflects a wider pattern in the literature on the economics and ethics of the increasing use of human (and to a lesser extent non-human) bodily matter, whether in the form of organs, cells, or fluids, in the science and business of contemporary biomedicine and biotechnology. Some biological matter - stem cells or genes, oocytes, or blood - have tended to be privileged over others such as breast milk (see Swanson 2014), positioning them as the key "biotechnical actors" (Waldby 2002) of the late twentieth and early twenty-first century. In this paper, we argue that saliva has emerged as an increasingly important "biotechnical object" that circulates in new commercial, scientific and social relations, as what Bronwyn Parry (2004) calls, a "bioinformational proxy". 
In our paper, we set out to redress the way that saliva has tended to be overlooked or considered less relevant to social science analyses of biocapital by documenting the biotechnical history of saliva across different fields of scientific research. We trace how, like other bodily substances, it has been opened up to "the micro-technical manipulation of productivity" (Waldby and Mitchell 2006, 32). Yet, saliva also has specific historical associations. Like blood, which might also be considered as a bioinformational proxy, saliva still retains a certain visceral quality that cannot be ignored, and it is still loaded with symbolism and associations that cannot be easily stripped away. Attending to saliva's social meanings over time, we focus on how expectoration, often viewed as a socially indecent act, is now one associated with discourses of self-empowerment and invocations to selfexpression and participation (Burgess 2015). As we show, the personal genomics company 23 andMe has promoted spitting as the means by which individuals gain genetic knowledge about their health and ancestry. However, by analysing YouTube "unboxing" videos posted by 23 andMe's users, we consider how spitting, in forming part of public representations and enactments of personal genomics, is also characterized by ambiguities around its visceral appearance and concealment in such videos.

We therefore argue in this paper that saliva has become a promissory substance whose place is no longer reserved only for the inner spaces of the body, but circulates outside the body across supply chains and online spaces, forming an important part of the contemporary bioeconomy.

\section{Biovalue, Bodies and Biocapital}

While for centuries, human bodies and body parts have long been of value to the pursuit of medical knowledge and experimentation, biomedical technologies and healthcare practices in the post-World War II period entailed making new uses of human biological matter in transplantation, reproductive medicine, and in cellular and genetic research. Since the 1980s and increasingly throughout the 1990s and 2000s, there has been significant interest in the commodification of the human body linked to the "incredible expansion of possibilities through recent advances in biomedicine [..] in tandem with the spread of global capitalism and the consequent speed at which patients, technologies, capital, bodies and organs can now move across the globe" (Scheper-Hughes 2001, 3). A series of bio-legal (Lynch and McNally 2009) changes to the status of bodily and biological matter in the 1980s gave rise to new opportunities to generate commercial value from genetically altered organisms, isolated gene sequences, and immortalized cell lines. In such cases, scientists and clinicians claimed intellectual property rights over such entities because they were considered "examples of human ingenuity and inventive effort", altered and improved by human labour (Tutton 2004, 25). Moreover, hospitals, universities and other institutions with banks of human biological samples found that they were now in possession of what Dorothy Nelkin and Lori Andrews $(1998,31)$ call a "capital resource". In the 1990s, venture capital-funded firms appeared in several countries seeking to build their business on the exploitation of tissue banks (Kaiser 2002). There was also a distinct global north-south dynamics to such developments: biotechnology firms located primarily in North America and Europe sponsored "gene prospecting", highly controversial expeditions to remote regions of the world, to collect blood samples from indigenous or other apparently isolated peoples for use in their research (Reardon 2005).

These changing uses of human organs, tissues, fluids, and cells have prompted bioethical and social scientific debate about their symbolic meanings, the basis on which they could be legitimately exchanged and transferred, and new analytical accounts of their changing 
economic value (Parry and Gere 2006). In their work, Nelkin and Andrews $(1998,31)$ note that the reason why commodification has proven contentious is because body parts are "loaded with cultural symbolism". As the ethicist Thomas Murray $(1987,37)$ explains, certain parts "bear the marks of personhood", and are as such "central to what characterizes living human persons, members of the human community". Medical historian Susan Lawrence $(1998,112)$ suggests that cultures have different "hierarchies of value" in relation to which bits of human bodies matter more than others: "hearts, blood, brains, and eyes, for instance, have long seemed more powerful, more central to personhood, more attuned to spiritual connections than hair, saliva, leg muscles, or kidneys". In the Western tradition, then at the top of the hierarchy are organs and blood, but not other parts such as fingernails, hair (although sometimes that might be the case) or urine, skin cells or saliva which are shed on a regular basis, and which are deemed to be no more than "scraps" (Lawrence 1998). Given the symbolic meanings of some parts of the human body, ethicists have argued that the only ethically acceptable way for organs or blood for example to be exchanged is as a "gift". As Murray (1987) suggests, this type of exchange involves "moral relationships" as opposed to contracts of the marketplace, imbued with notions of altruism, solidarity, and community. Such sentiments are also found in Richard Titmuss' ([1971] 1997) highly influential rendering of blood donation as a "gift relationship", in which he yoked together older cultural meanings of blood as conferring shared identity and ancestry, with welfarist concerns with universal health care (see also Tutton 2004).

While ethicists have sought to formulate various kinds of ethical frameworks in response to the commodification of human biological matter, sociologists and anthropologists have investigated the form this commodification takes in practice, whose bodies are subject to extractive processes, and the implications for subjectivity and social relations (Elliott and Abadie 2008; Cooper and Waldby 2014; Sunder Rajan 2008; Swanson 2014; Waldby 2002). Moreover, as Stefan Helmreich (2008) suggests, scholars have come to see that with the increasing commodification of biological matter in new capitalistic ventures, a new kind of capital has emerged called "biocapital". What marks this out from earlier uses of human bodies for transplantation, say, is that much of it is promissory: it is about the uses of such biological matter in research that will produce putative future benefits.

In her work on stem cell research, Catherine Waldby $(2002,310)$ for example addresses changing dynamics of value through her concept of biovalue to describe the "yield of vitality produced by biotechnological reformulation of living processes, to induce them to increase or change their productivity along specified lines". Stem cells extracted from embryos or adults, once manipulated in the lab, could offer up the possibility of transformative therapies for the sick. In their critique of Waldby's conceptualization of biovalue, Kean Birch and David Tyfield $(2013,308)$ further suggest that social scientists need to analyse "the knowledge and knowledge labor required to transform these fragments into commodities that are valuable, [..] which creates value and not the latent qualities of the biological material itself". In further work, Melinda Cooper and Waldby (2014) focus not on scientists and researchers' labour but on the clinical labour of socially marginalized groups who comprise what they call an "extensive yet unacknowledged labor force", who provide the life sciences industry with various bodily matter, from semen to gametes, and access to their bodies for drug experimentation.

Furthermore, one significant trend that both bioethicists and social scientists recognize is that commercial and scientific interest in human biological matter centres not only on the matter itself, but on the information - specifically, genetic information - contained within it. Bronwyn Parry (2004) argues that in the context of genomic research, biological matter has 
been revalued as an "informational resource". In her careful exposition of this process, Bronwyn Parry $(2004,64)$ observes that:

The idea that [..] biological material could [..] yield up genetic or biochemical information that could form the basis of commodifiable products and processes began to animate entirely new approaches to the collection and utilization of biological material that have proven to have serious economic, cultural and ethical consequences.

As Parry relates, with the introduction of DNA sequencing in the 1970s, scientists could translate whole organisms into new more mobile forms that could act as proxies for that larger organism, permitting some features to be captured but others lost, and this biotechnology also meant that what began "as something unquestionably corporeal in form becomes [..] progressively decorporealized, existing in the final analysis as what could only be described as a body of information, an archive of stored data or images" (Parry 2004, 68). Parry argues that a new category of object has emerged from these historical changes, what she calls "bioinformational proxies".

Throughout this literature, authors privilege certain bodily substances or parts such as stem cells, blood, organs, gametes, and their significance to analysing contemporary forms of biocapital. In this paper, we are concerned with one particular bioinformational proxy, one which Parry and others (Lawrence 1998; Nelkin and Andrews 1998; Murray 1987) have tended to either overlook or pause to consider only very briefly. This is saliva. Catherine Waldby and Robert Mitchell $(2006,26)$ comment on the status of saliva: they observe that saliva is easily commodified because it is regarded as "waste" and does not "signify the donor", and we might conclude, to echo Murray's terms, saliva is not central to what characterizes human persons as members of the human community. However, we suggest that saliva exemplifies Waldby and Mitchell's $(2006,26)$ own observation that "waste tissues have changed status in dramatic ways under the aegis of genetic biotechnology, which can transform even the most modest biological material into both a marker for the self and a potentially lucrative source of genetic material". Today, we find that saliva is no longer regarded as just another waste product, but this bodily substance has come to occupy a central position in contemporary biocapital.

While social scientific analyses of consumer genetic testing and of personal genomics, has focused a great deal on the assemblage of biotech and infotech, scholars have given less attention to the saliva collection kit and what that makes possible. In their work on the field of personal genomics and in particular of the company 23andMe, Anna Harris, Sally Wyatt and Susan Kelly (2012) do address the act of spitting, which they deem as a form of "free clinical labour". Informed by Terranova's arguments about "free labour" in relation to online participation activities, they wish to draw attention to how 23 andMe users, by producing and collecting their saliva and sending it to $23 \mathrm{ndMe}$ for processing, are involved in the "coproduction" of biovalue, providing the company with information from which it has established a valuable database that it subsequently sells to pharmaceutical companies (Harris et al. 2016). We do not dispute this reading, but wish to go further to delve into how, as with kidneys, livers, spleens, blood, embryos, brains, or breast milk, saliva too has its own interesting biotechnical history, which we outline below.

There are two aspects to saliva. The first concerns its scientific study and its place in the history of biomedical and biotechnological research and innovation. The second concerns its expectoration. We consider both of these aspects in the next part of the paper. 


\section{Situating Saliva in Society and Biomedicine}

We might begin by contrasting the idea that saliva is a waste product to Heather Merle Benbow's (2003) discussion of Immanuel Kant's concern with saliva as a vital fluid: that the responsible individual concerned with maintaining their good health would wish to preserve as much of it as possible within their bodies. Spitting, for example, would "waste" saliva and so diminish the "finite sum of life force" of the individual, but also open the person up to “external invasion". Benbow cites Mary Douglas' work on pollution, and her observation that fluids flowing out of (and possibly into other bodies) violate bodily integrity, and the boundaries between self and the other. Benbow sees in Kant's philosophy a strong concern with what she calls an "economy of fluids" in which flows must be tightly controlled and regulated so as to ensure vitality. Concerns with fluids and their flows long predated Kant. As Norbert Elias (1982) relates in The Civilizing Process, which describes the development of social manners since the Middle Ages in various European societies, expectoration moved from an act that everybody did more or less without too much regard, to one that was still done but with a lot more care and attention. Elias cites an anonymously authored guide to "Civilite Francaise" published in 1714 that cautioned:

"Frequent spitting is disagreeable. When it is necessary you should conceal it as much as possible [...] And whenever you do spit, you should put your foot on the saliva [...] Do not spit so far that you have to look for the saliva to put your foot on it" (Elias 1982, 131).

Furthermore, instruction dictated that one should not mix one's saliva with other liquids or fluids such that the saliva might re-enter the body, or that one's saliva would "fall on someone". Elias $(1982,131)$ notes that "disgust and nausea at the ejection of saliva intensified" by the middle of the nineteenth century and generally became taboo in polite European society. However, this was not a consequence of any scientific understanding of saliva as a possible vector of disease. Such a concern about the health effects of spitting only appeared much later, and, in any case, the taboo about spitting varied across cultures (Chapman 1995; Nyugen and Wong 2006). For instance, in the United States, even amongst the social elites, spitting was a common practice, often associated with those who chewed tobacco (Abrams 2013). However, at the start of the twentieth century, saliva became problematized and pathologized with the identification of tuberculosis (TB) as a bacterial disease in the late 19th century and the suspected role that "careless" and "promiscuous" spitting played in spreading it (Abrams 2013). Despite the clear links between poverty, poor housing and living conditions and the incidence of TB, most public health measures emphasized spitting as the way that the disease was spread and therefore became the focus of measures to control it (Abrams 2013). Spitting became associated - at least in terms of public health messages - with disease and social indecency, with a number of US states passing laws to make spitting in public an offence. But for workers employed in the mining industry or agriculture, spitting was deemed a healthy thing to do: it was a way to expel from their bodies harmful toxins such as dust or dirt (Abrams 2013). Therefore, saliva as a bodily substance might be connected in different ways to health and vitality: as something to be valued and preserved and as a danger to others. In a similar way to how scholars have thought of the exchange of blood, organs or other bodily substances in terms of sociality, saliva has too been intimately bound up with sociality, as we go on to show, albeit in different ways.

The scientific study of saliva and its biochemical and physiological properties can be traced to the end of the nineteenth century (Nyugen and Wong 2006). However, it was in the postWorld War II period that the field of salivary research developed more fully, with particular interest in its function and composition. Using the new molecular biology tools of the 1950s, 
such as the electron microscope and electrophoresis, researchers studied the cell biology of saliva, identifying and quantifying its amino acids, immunoglobins, and proteins. In contrast to the anti-spitting campaigns discussed above, the focus of this research has been much more on the protective functions of saliva against disease, ranging from its antifungal to antiviral properties (Mandel 1993). It was not until the 1980s, however, that research into salivary diagnostics took off, and in particular, the dental researcher Irwin Mandel's work did much to advance the field of salivary diagnostics (Malamud 1993). In his paper Salivary Diagnosis, Mandel (1993) wrote about the "tantalizing promises" of salivary diagnostics such as its use in drug and hormone monitoring, its use by psychiatrists to study methadone, and the use of saliva to screen for HIV infections and other antibodies and antigens. Saliva was described as "a mirror of the body" that reflects the body's emotional, hormonal, immunological, and neurological status as well as nutritional influences, and "[g]iven this broad spectrum of interactions and relationships, many diagnostics possibilities are worthy of exploration and evaluation" (Mandel 1993, 3). Since then, a variety of commercial applications have become available using salivary diagnostics, for example, at-home HIV tests (OraQuick), cortisol test kits to detect levels of stress, periodontal disease test (MyPerioPath®) and ovulation microscopes (see Wilkinson et al. 2015 for a study of ovulation tracking).

In recent years, salivary research has undergone its own "omicization" with the term "salivaomics" appearing in 2008, accompanied by initiatives to study the "salivary proteome", "transcriptome", "microRNA" (miRNA), "metabolome" and "microbiome" (Wong 2012), and with the expectation that saliva will be a good diagnostic tool to detect biomarkers associated with disease, thus linking saliva to visions of personalised medicine found in other scientific fields of endeavour (Hedgecoe 2004; Tutton 2014). Developments in the field of salivary research therefore mirror those of other fields to which science historians and sociologists have documented well (Fox Keller 2009; Kay 1996). Yet, while these scholars have tended to focus on proteins, genes and stem cells as "among the most privileged biotechnical actors of the $20^{\text {th }}$ century" (Waldby 2002, 305), saliva has equally emerged as an important bodily substance in today's bioeconomy, although it has received less scholarly attention.

Given our interests in this paper, it is saliva's career as a "bioinformational proxy" - as a source from which genetic information can be extracted - which is of particular interest. We can trace this development to the 1990s and the introduction of large-scale studies in molecular genetics and genetic epidemiology. At this time, there was a need for simpler, costeffective and reliable means of genomic DNA sample collection as an alternative to blood sampling that was thought to be expensive and an invasive procedure (Walker et al. 1999; Ilveskoski et al. 1998; Richards et al. 1993; Meulenbelt et al. 1995). While blood has traditionally been the preferred biomaterial for obtaining genetic information for research or for conducting genetic tests due to its high yield of DNA, other sources of genomic DNA have been examined including the sampling of buccal cells. Different collection methods were suggested including the use of oral rinses or "mouthwashes" (e.g. Lum and Marchand 1998) and buccal swabs (Thomson et al. 1992; Richards et al. 1993; Droog et al. 1996; Ilveskoski et al. 1998; Walker et al. 1999). However, although the buccal cell samples are easily obtained, the methods considered non-invasive, and it is possible to store samples for longer at ambient temperatures before DNA extraction, other researchers found that this collection method was not suitable for the genotyping of hundreds or thousands of markers due to a too low yield of DNA. Instead, researchers suggested the whole-saliva collection method (Quinque et al. 2006; Rogers et al. 2007; Hansen et al. 2007), as an alternative to blood sampling for HLA typing (Terasaki et al. 1998) and the DNA analysis of biomarkers (van Schie and Wilson 1997). These studies looked towards the forensic sciences that since 
the early 1990s had found saliva and saliva-stained materials such as stamps and envelopes, and even bite marks with saliva, to be good sources of DNA for human identification in certain forensic settings (Walsh et al. 1992; Allen et al. 1994; Sweet et al. 1997).

However, drawbacks of using whole-saliva as an alternative to blood were noted, for example, the large number of bacterial cells in saliva, where this problem of contamination primarily depends on how the saliva samples are kept and stored after collection (Quinque et al. 2006; Rogers et al. 2007; Hansen et al. 2007). In order to not compromise the quality of the DNA in the sample, buffer solutions have therefore been developed to stabilise the genomic DNA, and since the mid-2000s, biotech companies have developed and sold such whole-saliva collections kits with stabilizing buffer solutions, for example the companies DNA Genotek, Qiagen, and Norgen. In 2004, the North American company DNA Genotek introduced its Oragene saliva collection kit to the market, used amongst others by the personal genomics company 23 andMe. The kit consists of a vial with a DNA non-toxin stabilising reagent (HG-BCD) that is described, on its company website (www.dnagenotek.com), to minimize bacterial content in the saliva samples and preserve the DNA at ambient temperatures. DNA Genotek also writes that its collection kits are "Easy. Painless. Proven", and on DNA Genotek's Sample Collection Blog, as of March 11, 2015, the importance of biostabilisation is described in more detail:

All DNA Genotek products are built on a basic principle of cellular disruption and liquid-based stabilization, allowing the sampling process to be standardized and optimized. This is due to our unique stabilizing chemistry which is the foundation of our company. Each of our collection kits and reagents contain a chemistry that allows you to immediately stabilize a biological sample so that it cannot be affected by external factors, and all desired biological material is protected over time and temperature.

No longer considered a "waste" product, saliva re-emerges as a fragile bodily substance that needs protection. Yet, within this new "economy of fluids" (Benbow 2003), protection shifts from bodily control to biochemical control with the development of the stabilising buffer solutions, through which the biomaterial transforms into a high-quality, bio-technical substance open to further manipulation. In its new chemical composition, saliva is thus said to promise "high integrity" DNA as the chemical reagents are said to ensure a stabilised saliva sample that "is truly representative of the in vivo state of the donor [therefore] allowing you to have complete confidence in the accuracy of your discoveries", as claimed on DNA Genotek's Sample Collection Blog, as of March 11, 2015.

The developments in biotechnology have also transformed the (work)-flow and logistics of genomic DNA collection, and the infrastructure on which it relies. The chemical reagents used in the whole-saliva collection kits not only act to stabilise the DNA, but they also become a logistical infrastructure, as the chemical mixtures, in part, allow saliva samples to be shipped with regular mail, across countries and continents at ambient temperatures. On DNA Genotek's Sample Collection Blog, as of February 26, 2014, the company claims that its Oragene products have simplified shipping logistics, as with their collection kits, there is no longer a need for packaging and shipping DNA samples on dry ice as a way to stabilise the DNA. Saliva sample can be shipped without sample degradation, and there is no longer a need for freezers, electricity, and maintenance, i.e. cold chain transport and storage. This collection method, DNA Genotek claims, thus allows for "workflow flexibility", as in effect, saliva is turned into a bio-chemically engineered substance that is easily stored, highly mobile and "workable". Not only do the collection kits allow saliva's movement across spaces and over time through which it becomes yet another thing "on the move" (Sheller and Urry 2006), 
but through the process, the bodily substance also becomes something different: no longer a fragile substance, but a bio-technical fluid that promises convenience, reduced costs and biovalue.

This once insignificant bodily substance has thus to some extent become what DNA Genotek $(2003,14)$ anticipated in its patent application: "a standard source of DNA from an individual (to replace blood, the current standard)" with the place of saliva as a "standard source of DNA" reflected most vividly in the development of personal genetic testing services, which depend in part on the ease with which standardized saliva collection kits can be mailed to customers and used by them without expert assistance or additional clinical equipment to produce samples for DNA analysis. But as we have shown, saliva also circulates in and through a political system (Waldby and Mitchel 2006) and as an economic network of relations, through which this bodily substance is opened up to "the micro-technical manipulation of productivity" (Waldby and Mitchell 2006, 32). Yet, in addition to its productive capacities, the substance also comes with specific historical associations as scientific researchers also acknowledge (Nyugen and Wong 2006), and thus like blood, saliva still retains a certain visceral quality that cannot be ignored. Saliva is still loaded with symbolism and associations that cannot be easily stripped away. This becomes evident when we look at the context of "personal genomics".

\section{"Spit Performances"}

The emergence of "personal genomics" in 2007 represented an effort by a small number of companies to turn ongoing basic research into the role of gene variants in common, complex disease conducted on different population cohorts using complex methods of statistical association into a popular consumer service, offering users direct access to findings from the latest science that promised to elucidate their individual susceptibility to disease (Wray et al 2007). In marketing these services, companies were articulating a vision of personalized medicine as a form of consumer empowerment through self-knowledge of genetic risk (Tutton 2014). Access to personal genomic risk information would be empowering and enabling of change, permitting users to take action in light of the information they received to improve their future health. The development of saliva collection kits has been a vital part of the way that companies were able to offer this service precisely because they permit saliva as a "bioinformational proxy" - to be highly stable and mobile. But the work needed to produce saliva as a source of bioinformation is not confined to the biotechnical manipulations of companies like DNA Genotek, but also involves individuals who purchase the kits from personal genomics companies. It is this aspect to which we now turn by analyzing examples of a new form of public spitting that ostensibly shifts the register of expectoration from indecency and disgust to something much more positive.

The personal genomics company 23 andMe began selling its "Personal Genome service" direct-to-consumer in 2006. At the time, the service was priced at $\$ 999$, but the price has since come down to $\$ 199$ (or $£ 149$ in the UK). The saliva collection kits are sold online (www.23andme.com) and in the UK, they are also available in Superdrug stores. The kit consists of a box with a vial, biohazard bag and instruction leaflet (see fig. 1). After spitting into the vial and making the sample ready for travel, the customer will ship the box by courier to 23 andMe's contracted laboratory (LabCorp) in the US, and within a few weeks, they are able to access their genetic testing results via their 23 andMe account. This includes data on ancestry, health risks, genetic carrier status and genetic traits.

\section{[FIGURE 1 NEAR HERE]}


In 2008, to create attention around its new genetic testing product, 23andMe's co-founders Linda Avey and Anne Wojcicki organized so-called "spit parties". Two of them were held during one of the 2008 New York Fashion Weeks and during the 2008 World Economic Forum meeting in Davos, Switzerland. Guests including Rupert Murdoch and designer Diana von Furstenberg were invited for drinks and to hear about and try out 23andMe's service. At the 2008 World Economic Forum meeting, held in Davos, Switzerland, 23andMe had put up a booth in the main conference hotel for guests to come and learn about the service and get a free 23andMe testing kit, if they were to spit there and now. The New York Times columnist Thomas Friedman, singer and song writer Peter Gabriel, and fashion model Naomi Campbell were some of guests who took up 23andMe's offer to have their DNA genotyped. Pictures of guests spitting into the vials were taken during the events and later posted online. The "spit parties" and their representations in these pictures have circulated widely among the press and social media outlets and contributed to the hype around direct-to-consumer genetic testing and in particular the company 23andMe at the time. With these "spit parties", the act of spitting shifted from being a banal practice in a clinical context to become a fashionable event and promoted as an act of self-empowerment. The concept of a "spit party" has since travelled (or trickled down) to "non-elite users" (Harris et al. 2014) who record the spit event and upload the video to video-sharing websites such as YouTube. Harris et al. (2014) refers to these videos as "autobiologies" and situate them as part of a broader shift toward public stories about genetics and what Kate O'Riordan (2010) calls "the genome incorporated", i.e. how genomics move in and out of bodies and spaces.

The "spit performances" included in our sample are all videos from YouTube: 69 videos in total (see appendix 1). In August 2014 and again in June 2016, we searched the YouTube database for 23 andMe "unboxing" videos using the search word "23andMe". We excluded videos of users who do not engage in "unboxing" the 23andMe kit but who simply talk about the service, users who only report on their 23andMe results, promotional videos uploaded by 23 andMe or others, and demonstration videos of third party tools used to analyse 23 andMe data. In the majority of the videos sampled, YouTubers are alone yet speaking to and sharing their "23andMe experience" with an imagined audience. For example, in many of the videos, YouTubers will ask viewers to subscribe to their YouTube channel in order to be notified when new videos are uploaded, which is not simply a technical affordance, as Postigo (2016) notes, but also an essential part of the social structures on the platform, as subscribers are "the most common social currency on YouTube" (Postigo 2016, 338). Nonetheless, while individual YouTubers might be interested in growing their number of subscribers, the "spit performances" very well fit with how Marina Levina (2010: 1) describes personal genomics: as "discursively position[ing] itself within social-networking culture that emphasizes continuous and constant sharing of oneself with others". While 23andMe is not involved in the production of the YouTube videos that we have studied, the spit performances arguably contribute to and cannot be disassociated from 23andMe's social network (see also Harris et al. 2014). In this sense, the videos are performative in that they enact a certain reality of personal genomics, where spitting into a tube becomes a social media event.

In our analysis of the videos, we treat the videos as discursive texts (Potter and Wetherell 1987), where we focus on how spitting and saliva is described, treated, shown and reacted to, and how through this process, the bodily substance acquires new significance and meaning. We focus on speech, interactions, bodily expressions and graphics, and how these contribute to enacting spitting and saliva in particular ways. More specifically, we focus on dialogue between YouTubers and an imagined audience and other people present in the video and on interactions between YouTubers and the collection kit and their own saliva, including bodily expressions. We treat these as material and discursive acts that do something in the world - 
here, as we will discuss below, to enact spitting and saliva as fragile and interestingly disgusting, and spitting as an act of self-empowerment.

\section{Saliva's Fragility}

On its own, and without biochemical interference, as we discussed earlier, saliva is very much a fragile substance, which also becomes evident in the YouTube videos. "The hardest thing about this was collecting spit", a YouTuber explains. "You have to collect a tablespoon of spit that doesn't have any foam in it. Mine had some foam unfortunately, but I just collected enough clear spit and then let foam be at the top because I don't think there is anything I can do. I don't think I can take it out”, she says (\#38). The self-collection kit comes with an instruction leaflet that says: "Spit into funnel until the amount of liquid saliva (not bubbles) reaches the fill line". Spitting into a tube might at first seem quite straightforward. "It's very simple. You spit. But you don't produce bubbles", a YouTuber explains (\#46). However, when it comes to the actual spitting, producing a sample with no bubbles becomes less straightforward: "It's really hard to produce, as there cannot be any bubbles", the same YouTuber remarks later on in the video (\#46). While bubbles cannot be fully avoided, too many bubbles mean not enough liquid saliva to extract DNA from. Here, the bubbles turn saliva into a fragile substance that must be produced carefully. Tips, however, are shared on how to produce a good saliva sample such as rubbing the cheeks or thinking of food. Saliva's vitality and productivity thus get linked to a different kind of bodily control - not through the control and regulation of the act of spitting itself, but by controlling one's salivary glands.

Yet, producing a good saliva sample starts prior to sample collection with the instructions "do NOT eat, drink, smoke or chew gum for 30 minutes before giving your saliva sample", as written on 23andMe's instruction leaflet, and according to DNA Genotek's Sample Collection Blog, as of November 27, 2012, this is meant to ensure a high yield of DNA in the saliva sample. To be sure that it had been 30 minutes, a YouTuber used an alarm: "[buzzing] this is my alarm going off, saying that I have actually waited long enough to take the test", she explains (\#26). Another YouTuber reads the instructions, and adds: "I've actually had coke, probably about 20 minutes ago, so I'll wait to spit into this until it's been 30 minutes because they want to get an accurate representation, right" (\#42). Instructions are here carefully followed in order not to compromise the sample and to get good results. Another YouTuber attributes the viscosity of her saliva to the timing of sample collection. "Oh we have a little viscosity in my sample there", she says when taking off the vial cap and a bit of saliva comes out. "I didn't eat or drink for an hour before just in case", she explains (\#12). In the videos, saliva's fragility is carefully handled by reading and following the exact instructions as printed on the box.

Another YouTuber is also concerned that she might have messed up the sample collection by providing too much saliva: "It's going to come out", she says and her husband asks: "You've put too much spit in there?". "Oh man", she says. "Make sure not to put too much spit when you do it. It's coming out. I'm going to need a napkin", she says, and her husband makes a face. "I'm scared that I've messed it up", she continues (\#54). Another YouTuber has similar concerns about "doing it right" - although her concerns are not about overspilling, but about contaminating her sample. She shows the box and its contents to the camera, and reads from the instruction leaflet: "Obviously, I have to read all this so I don't accidently mess things up, as I do. [...] I don't want to open it up yet because I haven't washed my hands or anything and I don't want to accidently mess up anything and I haven't read everything through" (\#29). Whether it is about bubbles, food or drink, bacteria, too much saliva, not enough 
saliva, as the YouTubers collect their samples, saliva becomes configured as a fragile substance.

\section{[FIGURE 2 NEAR HERE]}

As YouTubers unbox the kit, they carefully follow the instructions printed on the inside of the box to make sure they are doing it right (fig. 2). The instructions are read aloud, often several times as YouTubers document the process with their mobile phones. This is a scripted practice (Harris et al. 2014) which means that clinical protocols have been inscribed in the DNA collection kits to ensure that users follow the "technoscientific scripts" (Timmermans and Berg 1997) that are otherwise usually overseen by trained professionals. The careful handling of saliva is thus part of the self-collection method that has been organised to ensure the optimal circulation of saliva. Once carefully sampled, saliva's fragility will now be managed by the biochemical solution that works to further control and regulate its vitality as the sample moves across state and national borders. Saliva's status then changes from fragile to stable.

\section{Interestingly Disgusting}

"This is pretty disgusting. And I would like to share this with you" (\#13), a YouTuber says while showing the vial with saliva up close to the camera. In another video with four students, a woman says to the others: "By the way, this is totally gross, but it is fun", and another replies: "Science can be gross and fun" (\#8). In another video, a YouTuber simply says: "Never said this was pleasant, just interesting" (\#66). The act of spitting still provokes feelings of disgust, yet at the same time, the event is also characterised by interest and excitement. In another video, the man asks his wife when spitting: "Did I gross you out yet?". She laughs. "Is it funny?" (\#9), he asks and smiles. While spitting and seeing others spitting into a tube provokes feelings of disgust, it is nevertheless accompanied by smiles, laughs and interest - spitting becomes interestingly disgusting, and in turn something to be shared on social media. While to some extent contradictory, as Sara Ahmed $(2004,84)$ notes in her research on "the cultural politics of emotion", disgust is deeply ambivalent, "involving desire for, or an attraction towards, the very objects that are felt to be repellent". The YouTubers are disgusted by their own saliva; yet at the same time also interested and drawn to this bodily fluid. In many ways, they are moved or turned towards and away from their own bodies (Ahmed 2004; Grosz 1994).

Another YouTuber also comments on her saliva's physicality. "You guys, this is probably the grossest thing I've ever done", she says and spits. "Without contest, the grossest thing [...] I don't want to get any spit on me", she says when taking of the cap. "Oh it's stringy", she adds and mixes her saliva with the liquid. "So I've made my spit much more liquidy and not syrupy. It sounds gross. Yeah, it's a tube of my spit" (\#42), she says. What makes saliva disgusting to this YouTuber is its consistency: it is wet and "stringy", and it is "syrupy", and importantly, also its potential contact with her hand. It is disgusting because it threatens to stick to her hand, as Ahmed $(2004,85)$ notes on disgust: "Disgust is clearly dependent upon contact: it involves a relationship of touch and proximity between the surfaces of bodies and objects". Saliva inside the mouth or when contained in the tube does not provoke disgust, but as soon as it flows elsewhere - outside the mouth, between fingers - it affects us differently (Ahmed 2004). Even though the source of their disgust is the YouTubers' own saliva, their body parts cannot be wholly separated from the body, as Elizabeth Grosz $(1994,81)$ argues:

"Detachable, separable parts of the body -urine, faeces, saliva, sperm, blood, vomit, hair, nails, skin - retain something of the cathexis and value of a body part 
when even they are separated from the body. There is still something of the subject bound up with them - which is why they are objects of disgust, loathing, and repulsion as well as envy and desire".

This is because, as Grosz $(1994,81)$ argues, we do not "simply have a body; rather, the body is always necessarily the object and subjects of attitudes and judgments". Although spitting is still in many ways considered socially indecent and "disagreeable" (Elias 1982), within this space, it also emerges as an act of interest and fascination.

\section{[FIGURE 3 NEAR HERE]}

When the bodily fluid flows back into the body, however, it is a different kind of disgust. In another video, a YouTuber spits into the tube, but he fills it above the "fill to" line (see fig. 3): "Oh oh, it says fill to this line. I actually filled more than this line, so I think I have to drink some of it", he says and asks jokingly to the woman who holds the camera: "Do I get a straw?", and then takes a sip of the vial. "Oh my God, you're so disgusting" (\#5), the woman strongly reacts. Here, the bodily fluid provokes feelings of disgust because it has become alien and foreign to the body. "Once outside, out for good", William I. Miller (1997) observes as he comments on the psychologist Gordon Allport's thought experiment that captures this "magical transformation":

"Think first of swallowing the saliva in your mouth, or do so. Then imagine expectorating it into a tumbler and drinking it! What seemed natural and "mine" suddenly becomes disgusting and alien. Or picture yourself sucking blood from a prick of your finger; then imagine sucking blood from a bandage around your finger! What I perceive as separate from my body becomes, in the twinkling of an eye, cold and foreign" (Allport in Miller 1997, 97).

The moment of spitting, however, is not shown on camera in all of the videos, but nonetheless commented on. "Perhaps, you don't want to see me do that [spitting], so we'll pause while I am spitting" (\#23), a YouTuber says to the camera, and another says: "I guess I could do it now in front of the camera, but I think that's a bit disgusting, so I am not going to do that", and the text "Not Happening" appears (\#37). In 43 out of the 69 unboxing videos on YouTube that we have studied, the act of spitting is not shown to the viewers, although in 18 of those 43 videos, the YouTubers return to show the full vial to the camera. "Alright, so I am going to pause the video, and me and my husband are going to do our part. Nobody wants to see us spit in a cup, right, so we'll be right back", a YouTuber says, and the video returns: "Okay, we're back. We've spat. You don't want to see our spit, but here we are", she says and holds up the full vials to the camera (\#62).

Whether the moment of spitting is recorded on camera and shown to viewers or not, the act of spitting emerges as an exceptional and exciting event to be commented on and/or shared on social media. Although still disgusting, the act of spitting becomes associated with excitement and coolness: "Oh, it's like those oil and coloured water experiments in elementary middle school science. Very cool", a YouTuber says, when looking closely at her saliva sample. She holds up the sample to the camera. "This is about to become my 23andMe data. Okay, this is very exciting", she adds (\#12). In the YouTube videos, the interestingly disgusting event of spitting then acquires cultural value, and as the bodily substance comes to circulate across and within online spaces, its biovalue gets entangled with cultural value, arguably also of commercial interest and value to 23 andMe.

\section{The Promise of Self-Empowerment}


The practice of personal genomics is surely no ordinary event. Rather, spitting into a tube is an unusual event characterised by excitement and anticipation. "I'm just really excited about this, because it means that I am a little closer to finding out things about myself that I don't already know", a YouTuber says (\#56), and another similarly explains: "I'm excited. This looks like fun. I can't wait to tell you all the stuff that I've learned [...] They [23andMe] can find genetic traces of where our ancestors are from", she explains and adds: "Isn't that cool". She goes on to list the traits 23andMe tests for. "I'd love to see how much of that is going to be true. That's crazy", she adds (\#38). For many of the YouTubers, the excitement of personal genomics lies in the expectation to learn something new about themselves - whether it is their health risks, genetic traits or ancestry. "I am super excited. My mom was adopted, so we don't know anything about her side, so that's why I've chosen to take this DNA kit", another YouTuber explains. "I've also ordered a DNA kit for my mom", she adds. "She is super excited because she'll be getting one about her and her parents, so pretty cool" (\#26). Another YouTuber also explains that her dad is adopted: "I've been growing up knowing only half of my identity, half of my DNA, half of whatever you want to call it. I've grown up only knowing half of where I am from, so I've decided to learn more about the half I know nothing about. [...] I'll find out more about me and where I come from. I am excited", she says and goes on to spit in the funnel (\#40). Spitting is here re-framed as the first step towards this kind of self-knowledge, and as an act that is no longer a banal practice, but one that is associated with excitement and fascination. "I'm mailing off my saliva to California", a YouTuber says with excitement. "I think this is the coolest thing in the universe", she adds (\#14).

Its "coolness" and simplicity here becomes associated with a kind of empowerment. "I always thought genetic testing would be complicated and expensive, where you had to go to some lab with hooded scientists, but we live in 2016 and it's actually as simple as a little box being shipped to your door", a YouTuber explains (\#48). "This is really simple", another YouTuber says and shows the vial to the camera. "All you have to do is spit into this funnel thing", she explains (\#45). As the extracts from the YouTube videos show, the saliva selfcollection method promises both ease and convenience: there are no clinicians to take a sample; instead, you spit into a tube and mail off the sample to the lab. The self-collection method thus becomes significant to the promissory value of personal genomics, as it promises a form of empowerment: no involvement of doctors or "hooded scientists". Instead, you do it yourself.

Yet, while excitement and discourses of empowerment dominate the YouTube videos, they are necessarily entangled in wider discourses and practices of digital health where "doing it", as Jeremy A. Greene $(2016,307)$ notes, "means becoming more active in one's own diagnosis circumventing the doctor, and 'yourself' means the patient-consumer". As a result, the self-collection method arguably gets conflated with empowerment, and empowerment coopted by corporate interests.

\section{Conclusion}

In the paper, we hope that we have shown that looking at saliva fills a gap in the literature on the relationship between biomedical innovation and bodily parts by exploring the increasingly important role that saliva plays as a "bioinformational proxy" (Parry 2004). From a vector of disease, saliva has become re-valued as a highly flexible and portable substance that is easily sourced and is not characterized by the same kind of ethical charge which accompanies other bodily tissues. Becoming a bio-chemically engineered substance, this bodily matter's promissory value is thus derived from its biotechnical capacity to travel, 
to be mobile and "on the move", and more precisely, its flow across spaces is enabled, amongst other things, by the self-collection DNA kits that form part of its commodity process that spans the global: supply chains as well as social media.

As we have shown, saliva has been described as "a mirror of the body" (Mandel 1993) - or a spitting image of the body that, as a metaphor, today fits into visions and expectations of future medicine. No longer seen as "waste", the bodily fluid instead emerges as a key biotechnical object for biomedicine and not least the bioeconomy, and in particular personal genomics. Yet, as we have been shown, saliva's status as a productive biomaterial hinges on its transformation into a stable biomaterial. Such process is made possible by biotech companies such as DNA Genotek that tackle saliva's fragility with biotechnical engineering in a tube, and in turn, saliva is made to move conveniently across spaces: from individual homes around the global to laboratories in the US. The self-collection method with its embedded workflow then adds to saliva's productivity, not only through intensifying its "self-maintaining capacities" (Waldby 2002, 310), but also through the reorganisation of labour. Saliva's vitality is therefore not only engineered in the laboratory, but it is a process that starts with users carefully sampling their saliva at home to then ship off the now stable biomaterial by courier. The study then points to how the logistics of saliva emerges as an important material practice, and indeed key to personal genomics services with the selfcollection method playing a key role in mobilising saliva as a vital fluid.

How saliva travels therefore matters to its promissory value as does the affordance of sharing spitting as an event on social media. In his comment on 23andMe's spit parties, Gisli Palsson $(2009,12)$ adds how " $[\mathrm{t}]$ he emphasis [...] is no longer on spitting at someone (usually a gesture of contempt) but on the conviviality of spitting with a fellow human being, for the purpose of celebrating biosocial bonds, for founding social networks based on bodily signature". The YouTubers, in a similar way, also "publicly celebrat[e] both their self and their genome, stag[e] their persona and their bodily essence for the [social] media" (Palsson 2009 , 12). The "unboxing" videos are thus meant to be spitting images of the YouTubers.

What our study then highlights is how the act of spitting has emerged as a public event to celebrate on social media, because it is considered "cool" and empowering to do, and in turn, spitting can then be said to have found new social value as these spitting events come to circulate in and through online spaces and social networking platforms. Here, the bodily matter becomes situated in "an economy of fluids" where the outward flow of saliva is seen, not only as disgusting, but as "interestingly disgusting", and while spitting is still characterized by awkwardness and unease, this is in part what makes spitting into a tube an "interestingly disgusting" event, exactly to be shared on social media. Yet, this must necessarily be understood in part due to how the act of spitting becomes situated in a social media economy that celebrates self-expression and participation, and where the spitting events (i.e. spitting on camera) in many ways become another artefact of digital culture, and importantly, also part of 23andMe's “infrastructures of public-ness" (O'Riordan 2013).

Our paper then highlights how saliva has emerged as an increasingly important biotechnical object as well as a potential change agent for future medicine, as its clinical and diagnostic capacities expand, and in turn its productivity manipulated in more clinical as well as commercial technologies. The study also points to how this bodily matter has been and still is intimately bound up with sociality, and in many ways, is partly transfigured by social media. Together - saliva as a biotechnical object and the "spit performance" - enact saliva as a promissory substance. 


\section{References}

Abrams, J. E. 2013. ““'Spitting Is Dangerous, Indecent, and against the Law!” Legislating Health Behavior during the American Tuberculosis Crusade." Journal of the History of Medicine and Allied Sciences 68 (3): 416-450

Ahmed, S. 2004. The Cultural Politics of Emotions. Edinburgh: Edinburgh University Press

Allen, M., T. Saldeen and U. Gyllensten. 1994. "PCR-based DNA typing of saliva on stamps and envelopes". Biotechniques 17 (3): 546-552

Benbow, H. M. 2003. "Ways in, Ways out: Theorising the Kantian Body”. Body and Society 9 (1): $57-72$

Birch, K., and D. Tyfield 2013. "Theorizing the Bioeconomy: Biovalue, Biocapital, Bioeconomics or . . What?". Science, Technology \& Human Values 38 (3): 299-327

Burgess, J. 2015. 'From 'broadcast yourself' to 'follow your interests': making over social media". International Journal of Cultural Studies 18 (3): 281-285

Chapman, S. 1995. "Great expectorations! the decline of public spitting: lessons for passive smoking?" British Medical Journal 311 (23-30 December):1685-86.

Cooper, M. and C. Waldby. 2014. Clinical Labor: Tissue Donors and Research Subjects in the Global Bioeconomy. Durham: Duke University Press

DNA Genotek. 2003. "Composition and Method for Obtaining Nucleic Acids from Sputnum". US Patent application no. US 7,482,116 B2

Droog, S., Hanning, EW., Pfotenhauer, JP. et al. 1996. "Isolation and storage of DNA for population studies". Fibrinolysis 10, suppl. 2: 29-30

Elias, N. 1982. The Civilizing Process. Blackwell Oxford.

Elliott, C, and R. Abadie. 2008. "Exploiting a Research Underclass in Phase 1 Clinical Trials." New England Journal of Medicine 358 (22):2316-2317. doi:10.1056/NEJMp0801872.

Fox Keller, E. 2009. The century of the gene: Harvard University Press.

Greene, J. A. 2016. "Do-It-Yourself Medical Devices: Technology and Empowerment in American Health Care". The New England Journal of Medicine 374 (4): 305-308

Grosz, E. 1994. Volatile Bodies: Towards a Corporeal Feminism. Bloomington: Indiana University Press

Groves, C., and R. Tutton. 2013. "Walking the tightrope: Expectations and standards in personal genomics." Biosocieties 8 (2):181-204. doi: 10.1057/biosoc.2013.1.

Hansen, T. V. O., M. K.. Simonson, F. C. Nielsen, et al. 2007. "Collection of blood, saliva, and buccal cell samples in a pilot study on the Danish nurse cohort: Comparison of response rate and quality of genomic DNA". Cancer Epidemilogy Biomarkers and Prevention 16 (10): 2072-2076

Harris, A., S. Wyatt, and S. Kelly. 2012. 'The Gift of Spit (and the obligation to return it)' in Information, Communication \& Society, DOI: 10.1080/1369118X.2012.701656

Harris, A., S. Kelly, and S. Wyatt. 2014. "Autobiologies on YouTube: narratives of direct-toconsumer genetic testing". New Genetics and Society: 33 (1): 60-78 
Harris, A., S. Kelly, and S. Wyatt. 2016. CyberGenetics: Health Genetics and New Media. Oxon: Routledge

Hedgecoe, A. 2004. The Politics of Personalised Medicine: Pharmacogenetics in the Clinic. Cambridge: Cambridge University Press.

Helmreich, S. 2008. "Species of Biocapital”. Science as Culture 17 (4): 463-478

Hogarth, S., G. Javitt, and D. Melzer. 2008. "The current landscape for direct-to-consumer genetic testing: legal, ethical and policy issues". Annual Review of Genomics and Human Genetics 9: 161-182

Ilveskoski, E., T. Lehtimaki, T. Erkinjuntti, et al. 1998. "Rapid apolipoprotein E genotyping from mailed buccal swabs". Journal of Neuroscience Methods 79 (1): 5-8

Kaiser, J. 2002. "Biobanks: Population Databases Boom, From Iceland to the U.S." Science 298 (5596):1158-1161.

Kay, L. E. 1996. The molecular vision of life: Caltech, the Rockefeller Foundation, and the rise of the new biology. Oxford University Press

Lawrence, S. 1998. "Beyond the Grave - the use and meaning of human body parts: a historical introduction." In Stored Tissue Samples: Ethical, Legal, and Public Policy Implications, edited by R. F. Weir, 111-142. Iowa City: University of Iowa Press.

Levina, M. 2010. "Googling your genes: personal genomics and the discourse of citizen bioscience in a network age" JCOM: Journal of Science Communication 9 (1)

Lum, A. and L. Marchand. 1998. "A simple mouthwash method for obtaining genomic DNA in molecular epidemiological studies". Cancer Epidemiology, Biomarkers and Prevention 7 (8): 719-724

Lynch, M. and R. McNally. 2009. "Forensic DNA databases and biolegality." In Handbook of Genetics and Society: Mapping the New Genomic Era, edited by P. Atkinson, P. Glasner and M. Lock, 283-301. London: Routledge

Malamud, D. 1993. "Introduction" in Saliva as a Diagnostic Fluids, edited by D. Malamud and L. Tabak. Annals NY Academy of Sciences 694

Mandel, I. D. 1993. "A Contemporary View of Salivary Research". Critical Reviews in Oral Biology \& Medicine 4 (3):599-604. doi: 10.1177/10454411930040034701.

McGowan, M., J R Fishman, and M A Lambrix. 2010. "Personal genomics and individual identities: motivations and moral imperatives of early adopters". New Genetics and Society 29 (3): 261-290

McGuire, A., CM Diaz, T Wang, and SG Hilsenbeck. 2009. "Social networkers' attitudes toward direct-to-consumer personal genome testing." American Journal of Bioethics 9 (6-7): $3-10$

Meulenbelt, I., S. Droog, G. Trommelen, D. Boomsma, and E. Slagboom. 1995. 'High-Yield Noninvasive Human Genomic DNA Isolation Method for Genetic Studies in Geographically Dispersed Families and Populations". American Journal of Human Genetics 57 (5): 1252-1254

Miller, W. I. 1997. The Antomy of Disgust. Cambridge Mass.: Harvard University Press

Murray, T. H. 1987. "Gifts of the body and the needs of strangers". The Hastings Center Report 17 (2): 30-38 
Nelkin, D. and L. Andrews. 1998. "Homo economicus: commercialisation of body tissue in the age of biotechnology". The Hasting Center Report 28 (5): 30-39

Nguyen, S. and D. Wong. 2006. "Cultural, behavioural, social and psychological perceptions of saliva: relevance to clinical diagnostics." CDA Journal 24 (4): 317-322.

O'Riordan, K. 2010. The Genome Incorporated: Constructing Biodigital Identity. Oxon: Routledge

O’Riordan. K. 2013. "Biodigital Publics: Personal Genomes as Digital Media Artefacts". Science as Culture 22 (4): 516-539

Parry, B. and C. Gere 2006. "Contested bodies: property models and the commodification of human biological artefacts". Science as Culture 15 (2): 139-158

Palsson, G. 2009. "Spitting Image”. Anthropology Now 1(3): 12-22

Parry, B. 2004. Trading the genome: Investigating the commodification of bio-information: Columbia University Press.

Postigo, H. 2016. "The socio-technical architecture of digital labor: Converting play into YouTube money". New Media \& Society 18 (2): 332-349

Potter, J. and M. Wetherell. 1987. Discourse and Social Psychology: Beyond Attitudes and Behaviour. London: SAGE Publications

Prainsack, B. J. Reardon, R. Hindmarsh, H. Gottweis, U. Naue, and J. E. Lunshof. 2008. "Personal genomes: Misdirected precaution." Nature 456 (7218):34-35.

Quinque, D., R. Kittler., M. Kayser, M. Stoneking, and I. Nasidze. 2006. "Evaluation of saliva as a source of human DNA for population and association studies". Analytical Biochemistry 353 (2): 272-277

Reardon, J. 2005. Race to the Finish: Identity and Governance in an Age of Genomics. Princeton University Press.

Richards, B., J. Skoletsky, A. P. Shuber, R. Balfour, R. C. Stern, H. L. Dorkin., R. B. Parad., D. Witt, and K. W. Klinger. 1993. "Multiplex PCR amplification from the CFTR gene using DNA prepared from buccal brushes/swabs". Human Molecular Genetics 2 (2): $159-163$

Rogers, N. L., Cole, S. A, Lan, Hao-Chang et al. 2007. "New saliva DNA collection method compared to buccal cell collection techniques for epidemiological studies". American Journal of Human Biology 19 (1): 319-326

Saukko, P M., M. Reed, N. Britten, and S. Hogarth. 2010. "Negotiating the boundary between medicine and consumer culture: Online marketing of nutrigenetic tests." Social Science \& Medicine 70 (5):744-753.

Scheper-Hughes, N. 2002. "Bodies for sale-whole or in parts". Body and Society 7 (2-3): 1-8

Sheller, M. and J. Urry. 2006. "The New Mobilities Paradigm". Environment and Planning A 38 (2): 207-226

Sunder Rajan, K. 2008. "Biocapital as an emergent form of life: speculations on the figure of the experimental subject." In Biosocialities, Genetics and the Social Sciences, edited by Sahra Gibbon and Carlos Novas, 157-187. London: Routledge.

Swanson, K. W. 2014. Banking on the Body: Harvard University Press. 
Sweet, D., A. Lorente, A. Valenzuela et al. 1997. "PCR-based DNA typing of saliva stains recovered from human skin". Journal of Forensic Sciences 42 (3): 447-451

Terasaki, P, D. Chia, and L. Sugich. 1998. "Saliva as DNA source for HLA typing". Human Immunology 59 (9): 597-598

Thomson, D. M., N. N. Brown, and A. E. Clague. 1992. "Routine use of hair root or buccal swab specimens for PCR analysis: advantages over using blood". Clinica Chimica Acta 207 (3): 169-174

Timmermans, S., and M. Berg. 1997. "Standardization in Action: Achieving Local Universality Through Medical Protocols”. Social Studies of Science 27 (2): 273-305

Titmuss, R, 1997. The Gift Relationship: From Blood to Social Policy. London: London School of Economics.

Tutton, R. 2004. "Persons, Property and Gift: Exploring Languages of Tissue Donation to Biomedical Research". In Genetic Databases: Socio-ethical Issues in the Collection and Use of DNA, edited by Richard Tutton and Oonagh Corrigan. London: Routledge.

Tutton, R. 2014. Genomics and the reimagining of Personalized Medicine, Ashgate: London

van Schie, Rob C. A. A. and Wilson, M. 1997. "Saliva: a convenient source of DNA for analysis of bi-allelic polymorphisms of Fcy receptor IIA (CD32) and Fcy receptor IIIB (CD16)". Journal of Immunological Methods 208 (1): 91-101

Waldby, C. 2002. "Stem Cells, Tissue Cultures and the Production of Biovalue." Health 6 (3):305-323.

Waldby, C. and R. Mitchell. 2006. Tissue economies: Blood, organs, and cell lines in late capitalism. Durham: Duke University Press

Walker, AH., D. Najarian, DL. White et al. 1999. "Collection of genomic DNA by buccal swabs for polymerase chain reaction-based biomarker assays". Environmental Health Perspectives 107 (7): 517-520

Walsh, D. J., A. C. Corey, R. W. Cotton, L. Forman, G. L. Herrin Jr., C. J. Word and D. D. Garner 1992. "Isolation of deoxyribonucleic acid (DNA) from saliva and forensic science samples containing saliva”. Journal of Forensic Sciences 37 (2): 387-395

Wilkinson, J., C. Roberts and M. Mort 2015. "Ovulation Monitoring and Reproductive Heterosex: Living the Contraceptive Imperative?". Culture, Health and Sexuality 17 (4): 454-469

Wong, D. T. 2012. "Salivaomics". The Journal of The American Dental Association 143, suppl. 10: 19S-24S

Wray, N. R., M. E. Goddard, and P. M. Visscher. 2007. "Prediction of individual genetic risk to disease from genome-wide association studies." Genome Research 17 (10):15201528. doi: 10.1101/gr.6665407.

\section{Appendix 1: YouTube video material}

1. "23andMe Unboxing Review + save 20\% Part 1", 11/07/2014 http://www.youtube.com/watch?v=siRPns5vQCk, accessed August 2014.

2. "23andme submissions for genetic testing - Day 169 ActOutGames", 20/11/2013 http://www.youtube.com/watch?v=xo5WEGVLtnE, accessed August 2014. 
3. "23andMe Overview and Tutorial", 14/06/2013 http://www.youtube.com/watch?v=qQIUD0k4lck, accessed August 2014.

4. "“I'm coming to America!" 23andMe DNA test", 22/05/2013 http://www.youtube.com/watch?v=q-0uG3gxTSA, accessed August 2014.

5. "23 and Me", 17/04/2013 http://www.youtube.com/watch?v=xf3BG-LnhL8, accessed August 2014.

6. "How to do 23 andMe", 12/01/2013 http://www.youtube.com/watch?v=tuNTPMKYhF0, accessed August 2014.

7. "23andMe genetic testing: My experience", 10/08/2010 http://www.youtube.com/watch?v=OV6eWmaXsgU, accessed August 2014.

8. "Singularity University 23andMe spit party", 23/06/2010 http://www.youtube.com/watch?v=EbcUEW0saOk , accessed August 2014.

9. “@23andMe unboxing and testing - part 1", 04/05/2010 http://www.youtube.com/watch?v=9zoO3eBAoiY, accessed August 2014.

10. "Salivette Party, 23andMe spit together!", 14/01/2010 http://www.youtube.com/watch?v=AaOJx_IwOho, accessed August 2014.

11. "23andMe line for tests kits at TEDMED", 29/10/2009 http://www.youtube.com/watch?v=29jxcxPOwTU, accessed August 2014.

12. "23andMe research revolution 2009 BEGINS! FIRST patient-driven genomic research campaign", 07/07/2009 http://www.youtube.com/watch?v=D8vBy2Ua81k, accessed August 2014.

13. "23andMe sample collection from Eric", 21/05/2009 http://www.youtube.com/watch?v=TSRlr606kw4, accessed August 2014.

14. "Mailing my spit to California - 23andMe", 05/12/2008 http://www.youtube.com/watch?v=juaRpGv3Bgk, accessed August 2014.

15. "23 and me", 10/05/2014 http://www.youtube.com/watch?v=WPSNilMMIgY, accessed August 2014.

16. “\#118”, 20/03/2014 http://www.youtube.com/watch?v=5fl6ToSF7Fk, accessed August 2014.

17. "23andMe sample collection", 20/10/2013 http://www.youtube.com/watch? $=\mathrm{JNbc} 1 \mathrm{kbdrz} 0$, accessed August 2014.

18. "23andMe", 23/09/2013 http://www.youtube.com/watch?v=Z8jJ02eMtvo, accessed August 2014.

19. "23andMe Part 1”, 19/08/2013 http://www.youtube.com/watch?v=uanVn8dQ1U0, accessed August 2014.

20. "23andMe DNA discovery test kit", 26/05/2013 http://www.youtube.com/watch?v=eN-wSzHWVnQ, accessed August 2014.

21. "23andMe package and sample tutorial", 31/01/2012 http://www.youtube.com/watch?v=psfiCciQjjw, accessed August 2014.

22. "Unboxing av DNA-kit från 23andme (på svenska)", 10/01/2012 http://www.youtube.com/watch?v=FXojbk4Djxk, accessed August 2014.

23. "23andMe DNA saliva test kit", 13/05/2011 http://www.youtube.com/watch?v=x3dI4O9BEPg, accessed August 2014.

24. "23andme.com saliva sample instructions", 09/01/2011 http://www.youtube.com/watch?v=LRoCvzYn9eM, accessed August 2014.

25. "23andMe", 29/04/2008 http://www.youtube.com/watch?v=Zt8ut26LMV4, accessed August 2014.

26. "23andme review part 1 of 3", 07/11/2013 http://www.youtube.com/watch?v=7oRByFWiIk, accessed August 2014. 
27. "23andMe (showing off the kit)", 24/02/2014 http://www.youtube.com/watch?v=W5TQrRaEWaE, accessed August 2014.

28. "[no title]", 04/07/2014 http://www.youtube.com/watch?v=Ms0F45A_EE0, accessed August 2014.

29. "23andMe IBD kit", 21/08/2014 http://www.youtube.com/watch?v=3odD_d6M4bc, accessed August 2014.

30. "Got to know the 23andMe \& Pfizer IBD DNA kit for study", 13/08/2014 http://www.youtube.com/watch?v=W8nuKLrVR14, accessed August 2014.

31. "overview 23andMe", 04/08/2014 http://www.youtube.com/watch?v=fDJ3NXBWvFc, accessed August 2014.

32. "23andMe", 30/10/2013 http://www.youtube.com/watch?v=5yGs7pH_pLY, accessed August 2014.

33. "analisis y review: genotipado con 23 andMe: primera parte: desempaquetado", 11/07/2013 http://www.youtube.com/watch?v=wvGg17_PddI, accessed August 2014.

34. "23 and me", 19/01/2013 http://www.youtube.com/watch? $\mathrm{v}=\mathrm{NgQEMlAHuEA}$, accessed August 2014

35. "23andMe genome kit unboxing", 27/10/2012 http://www.youtube.com/watch?v=DX_hGmr0QLM, accessed August 2014.

36. "23andMe unboxing", 19/05/2011 http://www.youtube.com/watch?v=DBSm7FW1RaI, accessed August 2014.

37. "It has arrived! 23 andMe from America to London UK (Colombian test kit", 19/06/2016 https://www.youtube.com/watch? $\mathrm{v}=\mathrm{mV}$ 96qj8qwFw, accessed June 2016.

38. "23 and Me", 07/06/2016 https://www.youtube.com/watch?v=DFPxDMQV4yI, accessed June 2016.

39. "23andMe Unboxing", 29/05/2016 https://www.youtube.com/watch?v=k5E3xODYGpQ, accessed June 2016.

40. "23 and Me DNA kit- review", 11/05/2016 https://www.youtube.com/watch? $\mathrm{v}=\mathrm{mGkJ} 38 \mathrm{fa} 4 \mathrm{Cw}$, accessed June 2016.

41. "What's in The 23andMe DNA kit? (Unboxing \& Guesses My Trini DNA Challenge)", 26/04/2016 https://www.youtube.com/watch?v=sboR4kweX-4, accessed June 2016.

42. "WATCH ME GET A DNA TEST - I put 23andMe and Ancestry.com to the test!", 15/04/2016 https://www.youtube.com/watch?v=ZJJ0DJNxZUY, accessed June 2016.

43. "23andMe", 15/04/2016 https://www.youtube.com/watch?v=eirzoR6vHgM, accessed June 2016.

44. "[ASMR] Genetic Testing/23andMe Unboxing/tapping/whispering”, 13/04/2016 https://www.youtube.com/watch?v=TBDhL_u9Q9g, accessed June 2016.

45. "23andMe Review and Results (and other cool tools for DNA geekery", 14/01/2016 https://www.youtube.com/watch?v=T322wBclxk\&list=PL_h2npdBeGlheYlFxE71Zj3UK_Qn0hflK, accessed June 2016.

46. "How to use 23andMe DNA kit", 23/03/2016 https://www.youtube.com/watch?v=fTqJn_Rzss0, accessed June 2016.

47. "23andME: Como Usar El Kit", 21/03/2016 https://www.youtube.com/watch?v=ru2Qg8m0Vkw, accessed June 2016.

48. "23andMe Genetic Test Experience 2016", 13/03/2016 https://www.youtube.com/watch?v=8RLwzbdPLfc, accessed June 2016.

49. "23andMe Sample \& Step by Step", 03/03/2016 https://www.youtube.com/watch?v=iSaKY4mJIYI, accessed June 2016.

50. "23andMe unboxing", 05/02/2016 https://www.youtube.com/watch?v=Okwr3Kqrr84, accessed June 2016. 
51. "23andMe adoptee, Health Questions Pre Results (Part 1", 23/01/2016 https://www.youtube.com/watch?v=8TRSnvAb-TI, accessed June 2016.

52. "My 23 and Me Experience (part 1"), 08/01/2016 https://www.youtube.com/watch?v=v3_MPFb93Qc, accessed June 2016.

53. "23andMe project - Box opening...", 06/01/2016 https://www.youtube.com/watch?v=AAu-oUIfm5I, accessed June 2016.

54. "23andMe Genome Test (The NYC Couple)", 04/01/2016 https://www.youtube.com/watch?v=Zgx0mHPP-RE, accessed June 2016.

55. "Faccio il Test del DNA - Sono Malato - 23andMe", 07/12/2015 https://www.youtube.com/watch?v=kYA9qvP5OoM, accessed June 2016.

56. "23andME experience and results 201", 14/11/2016 https://www.youtube.com/watch?v=AWYYb9EN670, accessed June 2016.

57. "23andMe DNA Collection Kit unboxing", 02/11/2015 https://www.youtube.com/watch? $\mathrm{v}=\mathrm{hsx} 1 \mathrm{~m} 9 \mathrm{hGU} 0 \mathrm{w}$, accessed June 2016.

58. "23andMe - ....", 06/10/2015 https://www.youtube.com/watch?v=9Wq87qY3fBw, accessed June 2016.

59. "I DID THE 23andME DNA TEST", 14/08/2015 https://www.youtube.com/watch?v=GvojYLpo3nE, accessed June 2016.

60. "23 and Me DNA instructions", 21/07/2015 https://www.youtube.com/watch?v=XiBfOYCACYA, accessed June 2016.

61. "23andMe DNA Test Kit - Quick Look", 05/07/2015 https://www.youtube.com/watch? $\mathrm{v}=\mathrm{HBc} 1 \mathrm{xlHBbcY}$, accessed June 2016.

62. "23andMe ancestry DNA test part 1", 01/03/2015 https://www.youtube.com/watch?v=rPJuedwF6po, accessed June 2016.

63. "23andMe genetic kit for ancestry - unboxing", 02/02/2015 https://www.youtube.com/watch?v=k5TkBjkMCa4, accessed June 2016.

64. “23andMe唾液の採取方法”, 29/01/2015 https://www.youtube.com/watch?v=eqXM277rU0, accessed June 2016.

65. "Opening box for 23andMe - Brazilian Asian dude in Canada before Xmas", 24/12/2014 https://www.youtube.com/watch?v= qGiyrl_Wk, accessed June 2016

66. "My 23andMe profile experience", 08/12/2014 https://www.youtube.com/watch?v=bt3-RtkvSJ0, accessed June 2016.

67. "Spucken fur die Wissenschaft (Teil 1/2)", 08/12/2014 https://www.youtube.com/watch? $\mathrm{v}=\mathrm{xWAKOUmvnls}$, accessed June 2016.

68. "FWS - genotyping - my 23andMe results", 29/10/2014 https://www.youtube.com/watch?v=ne281h1q204, accessed June 2016.

69. "23andMe - part 1", 13/09/2014 https://www.youtube.com/watch?v=NUTYr6VCGAM, accessed June 2016.

\section{Figures}

Figure 1: 23andMe collection kit (authors' own photo)

Figure 2: 23andMe collection kit with instructions (authors' own photo)

Figure 3: DNA Genotek vial (authors' own photo) 